\title{
Author Correction: Phase $1 / 2$ trial of SARS-CoV-2 vaccine ChAdOx1 nCoV-19 with a booster dose induces multifunctional antibody responses
}

Jordan R. Barrett (D), Sandra Belij-Rammerstorfer, Christina Dold, Katie J. Ewer (iD, Pedro M. Folegatti (D), Ciaran Gilbride, Rachel Halkerston, Jennifer Hill, Daniel Jenkin (D), Lisa Stockdale (D), Marije K. Verheul, Parvinder K. Aley, Brian Angus (D), Duncan Bellamy, Eleanor Berrie, Sagida Bibi, Mustapha Bittaye, Miles W. Carroll, Breeze Cavell, Elizabeth A. Clutterbuck, Nick Edwards (D), Amy Flaxman, Michelle Fuskova (D), Andrew Gorringe iD, Bassam Hallis, Simon Kerridge, Alison M. Lawrie, Aline Linder, Xinxue Liu, Meera Madhavan, Rebecca Makinson, Jack Mellors, Angela Minassian (D, Maria Moore, Yama Mujadidi (D), Emma Plested, Ian Poulton (D), Maheshi N. Ramasamy iD, Hannah Robinson, Christine S. Rollier (iD, Rinn Song (D), Matthew D. Snape, Richard Tarrant, Stephen Taylor (iD, Kelly M. Thomas (D), Merryn Voysey, Marion E. E. Watson (D), Daniel Wright (D), Alexander D. Douglas D, Catherine M. Green, Adrian V. S. Hill ID, Teresa Lambe (D), Sarah Gilbert D, Andrew J. Pollard (D) and the Oxford COVID Vaccine Trial Group*

Correction to: Nature Medicine https://doi.org/10.1038/s41591-020-01179-4, published online 17 December 2020.

In the version of this article initially published, the numbers of cells in the third sentence of the second paragraph of the Methods subsection 'Antibody-dependent neutrophil phagocytosis' $(500,000)$ and in the fifth sentence of the first paragraph of the Methods subsection 'Antibody-dependent monocyte phagocytosis' $(250,000)$ were incorrect. The correct numbers are 50,000 and 25,000 (respectively). The errors have been corrected in the HTML and PDF versions of the article.

${ }^{\star}$ A full list of authors and their affiliations appears at the end of the paper.

Published online: 6 May 2021

https://doi.org/10.1038/s41591-021-01372-Z

(c) The Author(s), under exclusive licence to Springer Nature America, Inc. 2021

\section{Author Correction: Emergence and clonal expansion of in vitro artemisinin-resistant Plasmodium falciparum kelch13 R561H mutant parasites in Rwanda}

Aline Uwimana, Eric Legrand (D), Barbara H. Stokes (D), Jean-Louis Mangala Ndikumana, Marian Warsame, Noella Umulisa, Daniel Ngamije, Tharcisse Munyaneza, Jean-Baptiste Mazarati, Kaendi Munguti, Pascal Campagne, Alexis Criscuolo BD, Frédéric Ariey, Monique Murindahabi, Pascal Ringwald, David A. Fidock, Aimable Mbituyumuremyi and Didier Menard (D)

Correction to: Nature Medicine https://doi.org/10.1038/s41591-020-1005-2, published online 3 August 2020.

In the version of this article initially published, affiliation 2 (Malaria Genetics and Resistance Unit, Institut Pasteur, Paris, France) was incorrect. The correct affiliation is 'Malaria Genetics and Resistance Unit-Institut Pasteur, INSERM U1201, CNRS ERL9195, Paris, France'. Also, in the first sentence in the first paragraph of the fifth subsection of Results ('Origins of the Rwandan Pfkelch13 $561 \mathrm{H}$ haplotype and its relationship to other $P$. falciparum populations'), the first part of the sample description (" 350 samples, comprising 25 Rwandan sequences and 10 Eritrean $P$. falciparum sequences generated for this study") was incorrect. The correct text is "...340 samples, comprising 25 Rwandan $P$. falciparum sequences generated for this study.... Finally, Fig. 1 was incorrect, and the number of worldwide isolates in the legend title (325) was incorrect. The corrected figure is presented here, and the correct number of worldwide isolates is 315. The errors have been corrected in the HTML and PDF versions of the article.

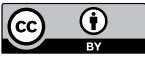

Open Access This article is licensed under a Creative Commons Attribution 4.0 International License, which permits use, sharing, adaptation, distribution and reproduction in any medium or format, as long as you give appropriate credit to the original author(s) and the source, provide a link to the Creative Commons license, and indicate if changes were made. The images or other third party material in this article are included in the article's Creative Commons license, unless indicated otherwise in a credit line to the material. If material is not included in the article's Creative Commons license and your intended use is not permitted by statutory regulation or exceeds the permitted use, you will need to obtain permission directly from the copyright holder. To view a copy of this license, visit http://creativecommons.org/licenses/ by/4.0/.
} 


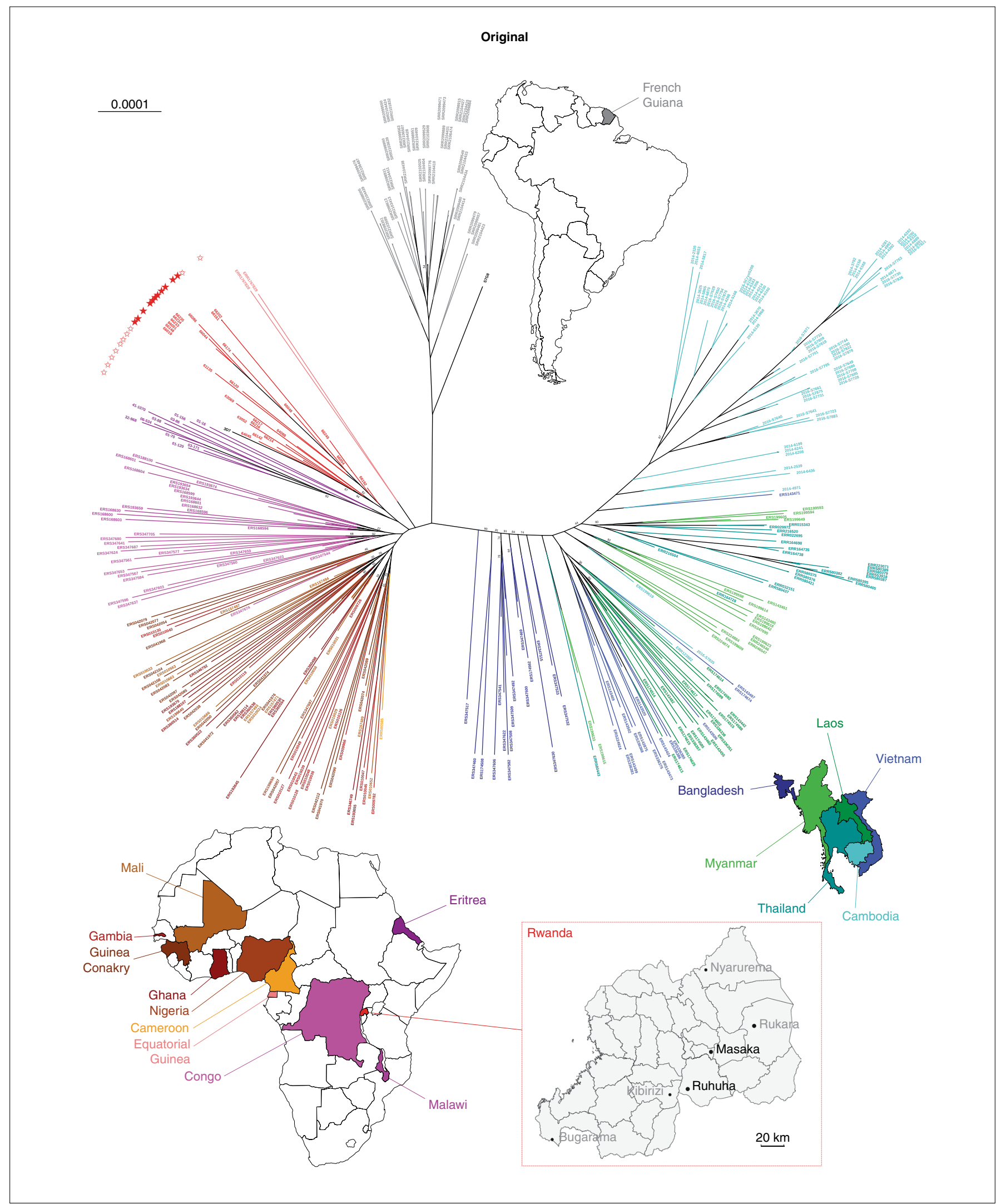




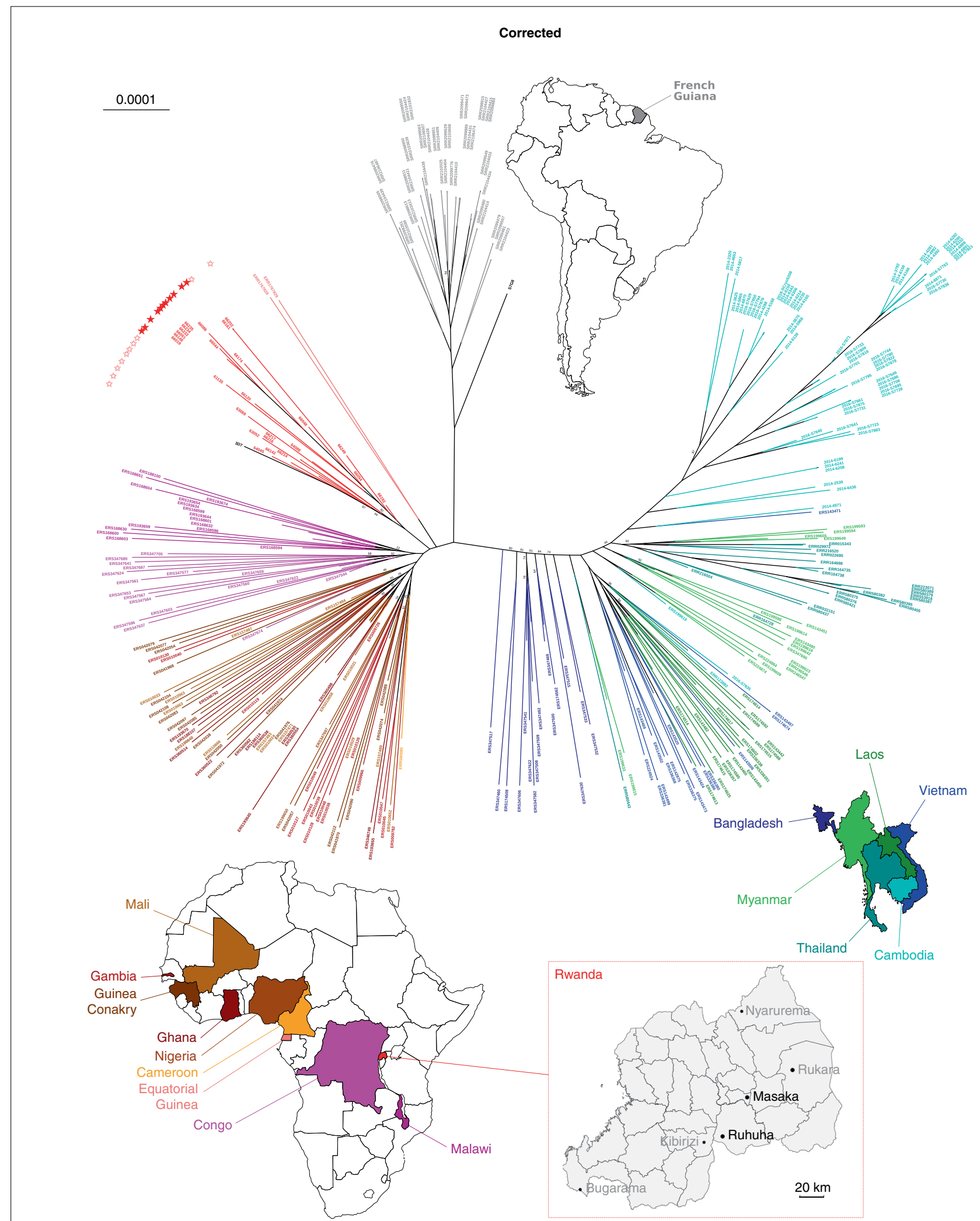

Fig. 1 | Original and corrected.

Published online: 27 May 2021

https://doi.org/10.1038/s41591-021-01365-y

() The Author(s) 2021 